\title{
Fecal Calprotectin: A Comparison of Two Commercial Enzymoimmunoassays and Study of Fecal Extract Stability at Room Temperature
}

\author{
Delia Acevedo ${ }^{\mathrm{a}, \mathrm{b}}$, Maria Pilar Salvador ${ }^{\mathrm{a}}$, Javier Girbes ${ }^{\mathrm{a}}$, Nuria Estan ${ }^{\mathrm{a}}$
}

\begin{abstract}
Background: The aims of the study were: 1) to compare the fecal calprotectin (fCal) assay results with Calprolab ${ }^{\text {TM }}$ ELISA (HRP) (Calpro AS) versus our routine method, Elia ${ }^{\mathrm{TM}}$ fluoroenzymoimmunoassay (Thermo Fisher), and 2) to determine whether the fCal assay results do not vary following storage of the extract at room temperature for 4 days with the Calpro AS buffer, this being the estimated shipment time from the home of the patient, and an aspect little studied to date.
\end{abstract}

Methods: The fCal was determined in 198 patients divided into three groups: inflammatory bowel disease (IBD), organic intestinal disease, and functional intestinal disorders. Fecal extraction was carried out using the Roche Diagnostics kit with the corresponding specific buffers.

Results: The fCal assay with the Thermo Fisher method was found to be more sensitive but less specific than with the Calpro AS technique. The positive predictive value was low (just over $50 \%$ ), though the negative predictive value was high (over 90\%) with both methods. The likelihood ratios revealed small but occasionally important preversus post-test differences. When we compared the two methods, the Spearman correlation coefficient $(\rho)$ was 0.819 (95\% CI: 0.768 $0.860)(\mathrm{P}<0.0001)$, reflecting a positive correlation. Similarly, when stratifying the fCal results into $<50 \mu \mathrm{g} / \mathrm{g}, 50-100 \mu \mathrm{g} / \mathrm{g}$ and $>100$ $\mu \mathrm{g} / \mathrm{g}$, the resulting Cohen's kappa coefficient was 0.7766 (95\% CI: 0.7025 - 0.8507), reflecting a substantial agreement between both methods. The stability of fCal was high in fecal extracts with the Calpro AS extraction buffer at room temperature for 4 days, which yielded a Spearman correlation coefficient of 0.951 (95\% CI: 0.933 $0.965)$, when the results were compared to those of the recent extracts $(\mathrm{P}<0.0001)$.

Conclusions: A positive correlation was observed between the two methods. In view of the high negative predictive value obtained with

Manuscript submitted November 19, 2017, accepted January 19, 2018

${ }^{a}$ Clinical Analysis Service, Dr. Peset University Hospital, Avenida Gaspar Aguilar, 90, 46440 Valencia, Spain

${ }^{b}$ Corresponding Author: Delia Acevedo, Clinical Analysis Service, Dr. Peset University Hospital, Avenida Gaspar Aguilar, 90, 46440 Valencia, Spain. Email: acevedo_del@gva.es

doi: https://doi.org/10.14740/jocmr3275e
$\mathrm{fCal}$, the presence of organic disease is highly unlikely in the presence of a normal concentration of this marker. We also confirmed the excellent stability of fCal in fecal extracts with the Calpro AS extraction buffer stored at room temperature. Thus, and for the sake of convenience and hygiene, it would be ideal for the patient to perform the extraction at home.

Keywords: Fecal calprotectin; ELISA; Inflammatory bowel disease; Functional intestinal disorder

\section{Introduction}

Abdominal pain is a common cause of consultation and medical attention in primary care and in the specialized gastroenterology setting and in some cases even requires hospitalization. A correct differential diagnosis between functional and organic disorders is therefore important, particularly if inflammatory bowel disease (IBD) is suspected. In this regard, a colonoscopy with biopsy should be performed to confirm the diagnosis and determine the degree of inflammation. These techniques are invasive procedures with a risk of complications for the patient and general anesthesia is also required in the case of pediatric patients.

The determination of fecal calprotectin (fCal) has recently become consolidated as a new and useful marker of IBD [1]. A number of studies have demonstrated an association between fCal levels and degree of inflammation, which is used to assess patient response to treatment and to predict the risk of relapse $[2,3]$.

Calprotectin, also known as L1-protein or S100A8/A9, is a small $(36 \mathrm{kDa})$ calcium- and zinc-binding protein mainly found within the cytoplasm of the polymorphonuclear leukocytes, representing $60 \%$ of the global cytosolic proteins [4]. By way of comparison, there is almost as much calprotectin in one granulocyte as there is hemoglobin in a red blood cell. The molecule is also found in smaller proportions in monocytes and reactive macrophages [5].

Binding to calcium increases the stability of calprotectin, which is resistant to proteolytic degradation due to the important calcium content in stools. It remains very stable in fecal samples for 4 - 7 days at room temperature [6]. Although the precise biological function of calprotectin has not been clearly 
established, it reportedly possesses bactericidal and fungicidal properties [7]. It is activated and released in the presence of infectious and/or inflammatory processes [8] and can be detected in serum, stools and other body fluids (saliva, synovial fluid, urine, etc.). Its fecal concentration is much higher (up to six-fold) than plasma levels [9].

The determination of fCal can help in establishing a differential diagnosis among organic intestinal diseases such as IBD, polyps, diverticula, nonsteroidal anti-inflammatory drugs (NSAIDs)-induced enteropathy, colorectal cancer, celiac disease, cystic fibrosis, enteritis of infectious origin or secondary to chemotherapy or immune suppression, and functional intestinal diseases such as irritable bowel syndrome. In this regard, fCal has been proposed as a non-invasive marker of acute flare-ups in IBD, for the monitoring of chronic inflammatory disease activity and treatment response or for the early detection of relapse [10].

In 1992, Roseth et al developed the first method for the determination of fCal [11], based on an enzyme-linked immunosorbent assay technique (ELISA). Since then, the method has been extensively validated and improved and is now easily measurable, reproducible and relatively inexpensive.

The aim of this study were to compare the new-generation Calprolab $^{\mathrm{TM}}$ Calprotectin ELISA (HRP) assay (Calpro AS) versus the Elisa ${ }^{\mathrm{TM}}$ Calprotectin fluoroenzymoimmunoassay (Thermo Fisher) and to evaluate the stability of fCal in fecal extracts stored with the Calpro AS extraction buffer at room temperature. The stability of calprotectin in fecal samples is known, but that of the extract (suspension with a buffer required for determining the protein) varies greatly from one manufacturer to another. Calpro AS specifies an extract stability of up to 5 days at room temperature, which would allow sample collection by the patient using adequate extraction tubes [12], followed by shipment to the laboratory. For the sake of comfort and hygiene, this practice would be very advisable for both patient and laboratory staff, as in other scenarios, such as the detection of occult blood in stools. It must therefore be confirmed that the results obtained do not vary following storage of the extract at room temperature for 4 days, this being the estimated shipment time from the home of the patient, and an aspect little studied to date.

\section{Materials and Methods}

A prospective observational study of fCal determinations in fecal samples was carried out at the Dr. Peset University Hospital (Valencia, Spain) between June and September 2016.

\section{Samples}

We consecutively processed samples with requests for fCal assay in 200 patients over 4 years of age in a period of approximately 3 months and referred from the primary care, specialized and hospital settings. The exclusion criteria were inadequate samples (because they had been collected in a buffer or transport medium) and scant sample material, since $100 \mathrm{mg}$ of fresh stools are needed. Following determination, two samples were excluded, one due to a failed result and the other to sample duplication, leaving a total of 198 samples.

Three extracts of the same fecal sample were prepared: one with Thermo Fisher buffer, one with Calpro AS buffer (comparative study) and a third with Calpro AS buffer to keep it at room temperature for 4 days (stability study). For organizational reasons, we do not determine fCal in our laboratory every day. Since Thermo Fisher does not recommend refrigeration, extracts are prepared and frozen immediately until analysis, always below 7 days; this technique is allowed by manufacturers, both Thermo Fisher and Calpro AS (as shown in Table 1), without affecting the quality of the results. In this case, we use the term "recent", unlike the same procedure that is used after keeping the extracts at room temperature.

The final number of samples in the stability study was lower $(n=150)$, as the samples on Tuesday and Wednesday could not be frozen 4 days later as it was weekend (non-working days) and were therefore excluded.

Since the cut-off point for infants under 4 years of age is $>200-250 \mu \mathrm{g} / \mathrm{g}$ [13-17], these patients were excluded from the study in an attempt to harmonize diagnostic criteria with fCal. Above that age, fCal values are the same as for adults [9, $13,18]$. A complete case history was compiled for all patients and the definitive diagnosis was based on different procedures: clinical data, laboratory tests (e.g., blood biochemistry, celiac disease serology, determination of parasites and their eggs in stools), plain abdominal X-rays, abdominal ultrasound, upper digestive endoscopy and colonoscopy. The patients were diagnosed with functional gastrointestinal disorders according to the Rome III clinical criteria [19] and after other organic conditions based on the normality of the complementary test findings had been ruled out. The diagnosis of IBD was based on clinical, endoscopic and histological criteria.

The patients were therefore divided into three groups: 1) IBD: 55 patients, 24 of whom presented Crohn's disease (CD) and 31 ulcerative colitis (UC); 2) organic intestinal diseases: 36 patients; the distribution was: bacterial colitis $(n=3)$, intestinal polyps $(n=6)$, diverticulitis $(n=4)$, hemorrhoids ( $=3)$, non-specific colitis $(\mathrm{n}=3)$, lactose intolerance $(\mathrm{n}=2)$, celiac disease $(\mathrm{n}=2)$, alpha-1-antitrypsin deficiency $(\mathrm{n}=1)$, Helicobacter pylori gastritis $(\mathrm{n}=2)$, gastroesophageal reflux $(\mathrm{n}=2)$, Giardia lamblia cysts $(\mathrm{n}=1)$ and NSAIDs-induced enteropathy $(\mathrm{n}=7)$; 3 ) functional gastrointestinal disorders: 107 patients, the majority presenting non-specific symptoms in the form of pain, abdominal bloating, dyspepsia, chronic diarrhea with or without constipation episodes (mixed habits), and with no organic disease as evidenced by the aforementioned procedures, diagnosed as functional gastrointestinal disorders and irritable bowel syndrome.

The degree of IBD was evaluated using two indices: 1) the simple clinical colitis activity index (SCCAI) for UC [20], which considers disease symptoms over the last week. This index comprises six domains and categorizes two types of patients: those with inactive disease (SCCAI score $<5$ ) and those with active disease (SCCAI score $\geq 5$ ); and 2) the Harvey-Bradshaw index (HBI) for CD [21], which comprises five domains and contemplates four categories: remission (score $<$ 5), mild disease (score 5 - 7), moderate disease (score 8 - 16) 
Table 1. Evaluation of the Stability of the Fecal Extracts in Different Fecal Calprotectin Tests

\begin{tabular}{|c|c|c|c|c|c|}
\hline Test & Method & Extraction device & $-20{ }^{\circ} \mathrm{C}$ & $2-8^{\circ} \mathrm{C}$ & $\begin{array}{l}\text { Room } \\
\text { temperature }\end{array}$ \\
\hline $\begin{array}{l}\text { Quick Check Gernon (RAL, } \\
\text { Barcelona, Spain) }\end{array}$ & $\begin{array}{l}\text { Qualitative } \\
\text { immunochromatography }\end{array}$ & RAL & $\mathrm{NE}$ & $\mathrm{NE}$ & $\mathrm{NE}$ \\
\hline $\begin{array}{l}\text { CalDetect test 50/200 (Preventis } \\
\text { GmbH Bensheim, Germany) }\end{array}$ & $\begin{array}{l}\text { Semi-quantitative } \\
\text { immunochromatography }\end{array}$ & Preventis & $\mathrm{NE}$ & 7 days & $\mathrm{NE}$ \\
\hline Calfast (Eurospital, Trieste, Italy) & $\begin{array}{l}\text { Quantitative } \\
\text { immunochromatography }\end{array}$ & Eurospital & 3 months & 2 days & $\mathrm{NE}$ \\
\hline $\begin{array}{l}\text { Calprotectin turbo (Buhlmann, } \\
\text { Schonenbuch, Switzerland) }\end{array}$ & Turbidimetric immunoassay & $\begin{array}{l}\text { Smart-Prep } \\
\text { Buhlmann }\end{array}$ & $>24$ months & 7 days & $\mathrm{NE}$ \\
\hline $\begin{array}{l}\text { Calprotectin ELISA (Buhlmann, } \\
\text { Schonenbuch, Switzerland) }\end{array}$ & Enzymoimmunoassay & Calex Cap Buhlmann & $\mathrm{NE}$ & $\mathrm{NE}$ & 3 days \\
\hline $\begin{array}{l}\text { Quantitative Fecal Calprotectin } \\
\text { (DIASource, Ottignies- } \\
\text { Louvain-la-Neuve, Belgium) }\end{array}$ & Enzymoimmunoassay & DIASource & Long period* & 3 days & $\begin{array}{l}\text { During } \\
\text { transport* }\end{array}$ \\
\hline $\begin{array}{l}\text { Calprolab }{ }^{\mathrm{TM}} \mathrm{HRP} \text { (Calpro } \\
\text { AS, Lysaker, Norway) }\end{array}$ & Enzymoimmunoassay & Roche & $>24$ months & $>5$ days & $\mathrm{NE}$ \\
\hline $\begin{array}{l}\text { Elia Calprotectin (Thermo } \\
\text { Fisher, Uppsala, Sweden) }\end{array}$ & Fluoroenzymoimmunoassay & Roche & 3 months & $\begin{array}{l}\text { Not } \\
\text { recommended** }\end{array}$ & $\mathrm{NE}$ \\
\hline $\begin{array}{l}\text { LIAISON }^{\circledR} \text { Calprotectin } \\
\text { (DIASorin, Saluggia, Italy) }\end{array}$ & $\begin{array}{l}\text { Chemiluminescent } \\
\text { immunoassay }\end{array}$ & LIAISON DIASorin & $\begin{array}{l}\text { Not } \\
\text { recommended }\end{array}$ & 7 days & $4 \mathrm{~h}$ \\
\hline
\end{tabular}

NE: not evaluated by the manufacturer. ${ }^{*}$ Number of days not specified. ${ }^{*}$ May lead to decreases in fecal calprotectin concentration.

and severe disease (score $>16)$.

A total of 16 patients with $\mathrm{CD}$ presented active disease $(66.7 \%)$ versus 22 with UC (70.9\%).

\section{Methods}

Two methods were used: 1) The Elisa ${ }^{\mathrm{TM}}$ Calprotectin fluoroenzymoimmunoassay, read with Immunocap 250 (both by Thermo Fisher Scientific, Inc., Phadia AB, Uppsala, Sweden), which is our laboratory's routine technique. 2) The Calprolab ${ }^{\mathrm{TM}}$ Calprotectin ELISA (HRP) (Calpro AS, Lysaker, Norway), read with the Zenit UP automatic ELISA microplate analyser (Menarini Diagnostics, Florence, Italy).

The measurement ranges are $5-2,500 \mu \mathrm{g} / \mathrm{g}$ for Calpro AS and $15-3,000 \mu \mathrm{g} / \mathrm{g}$ for Thermo Fisher. The cut-off point for both techniques is $50 \mu \mathrm{g} / \mathrm{g}$ stools, but it is accepted by different authors [22-24]: $<50 \mu \mathrm{g} / \mathrm{g}=$ negative; $50-100 \mu \mathrm{g} / \mathrm{g}=$ indeterminate, requiring repetition after a short period of time, and $>$ $100 \mu \mathrm{g} / \mathrm{g}=$ positive. Accordingly, we classified the results into these three categories and calculated Cohen's kappa coefficient with the following agreement levels: $<0=$ no agreement; $0-0.2=$ none to slight; $0.2-0.4=$ fair; $0.4-0.6=$ moderate; $0.6-0.8=$ substantial; and $0.8-1=$ almost perfect [25].

In assessing the level of agreement between quantitative variables, we used the Analyse-it statistical application (www. analyse-it.com) for Passing-Bablok linear regression analysis, Bland-Altman plot and calculation of the Spearman correla- tion coefficient $(\rho)$, while the VassarStats application (http:// vassarstats.net) was used to determine Cohen's kappa coefficient. All the tests were significant with a $\mathrm{P}<0.05$.

In both cases, fecal extraction was performed using the Smart-Prep kit (Roche Diagnostics, Hoffmann-La Roche, Rotkreuz, Switzerland), and the specific extraction buffer of each method.

Temperature was controlled using a PCE-HT temperature and humidity recorder (PCE Instruments Iberica, Tobarra, Albacete, Spain), with recordings made every hour during the evaluation period.

The study was approved by the Ethics Committee of our hospital (ref. 100/2016).

\section{Results}

\section{Comparison of the assays}

The mean patient age was 29 years (median 27.5; range 4 - 81). The fCal results are shown in Table 2, distributed according to diagnosis. Overall, considering the cut-off point of $50 \mu \mathrm{g} / \mathrm{g}$, 82 samples (41.4\%) were found to be positive with Calpro AS versus 90 samples $(45.4 \%)$ with Thermo Fisher. These figures fell to 63 samples $(31.8 \%)$ and 78 samples $(39.4 \%)$, respectively, considering the cut-off point of $100 \mu \mathrm{g} / \mathrm{g}$.

The Passing-Bablok adjusted scatter plot of the fCal re- 
Table 2. Fecal Calprotectin Results (in $\mu \mathrm{g} / \mathrm{g}$ Stools) in Different Diagnostic Groups

\begin{tabular}{|c|c|c|c|c|c|c|c|c|c|}
\hline \multirow{2}{*}{ Disease } & \multirow{2}{*}{ C/T-F, n } & \multirow{2}{*}{$\mathrm{C}$, range } & \multirow{2}{*}{ T-F, range } & \multirow{2}{*}{$\mathrm{C}$, median } & \multirow{2}{*}{ T-F, median } & \multicolumn{2}{|r|}{ C } & \multicolumn{2}{|c|}{ T-F } \\
\hline & & & & & & mean & $95 \%$ CI & mean & $95 \%$ CI \\
\hline IBD & 55 & $5-2,179$ & $15-4,247$ & 233 & 221 & 587 & $393-781$ & 419 & $236-603$ \\
\hline Ulcerative colitis & 31 & $7.5-2,179$ & $15-4,247$ & 338 & 259 & 709 & $421-998$ & 514 & $209-801$ \\
\hline Non-IBD organic diseases & 36 & $5-1,304$ & $15-1,157$ & 65 & 60 & 390 & $154-614$ & 264 & $142-431$ \\
\hline
\end{tabular}

n: sample numbers; C/T-F: both methods; C: Calpro AS; T-F: Thermo Fisher. IBD: inflammatory bowel disease.

sults obtained with Calpro AS versus Thermo Fisher is shown in Figure 1a. The y-intercept does not pass through 0 (from 6.6056 to 9.3446 ), thus reflecting systematic differences between the two methods, although the Spearman correlation coefficient $(\rho)$ was 0.819 (95\% CI: 0.768 - 0.860) $(\mathrm{P}<0.0001)$, indicating good correlation. The difference plot of Bland-Altman between the fCal values by Thermo Fisher and Calpro AS showed a linear relationship between the variables at low fCal values, and greater dispersion at higher fCal (Fig. 1b) values. The histogram of the differences between the fCal determined by Thermo Fisher and Calpro A shows a normal distribution (Fig. 1c).

The fCal results distributed into the three categories are shown in Table 3. Cohen's weighted kappa coefficient was 0.7766 (95\% CI: 0.7025 - 0.8507).

Table 4 shows the diagnostic tests for IBD with both methods and cut-off points. Sensitivity in detecting IBD was greater with Thermo Fisher than with Calpro AS, although in contrast specificity was greater with the latter technique. Similar findings applied to non-IBD organic diseases $(76.2 \%$ versus $65.7 \%$, respectively) and functional disorders (82.4\% versus $72.2 \%)$ (data not shown). Calpro AS also exhibited greater accuracy than Thermo Fisher in relation to both cut-off points. The positive predictive value (PPV) was low (just over 50\%), although in contrast the negative predictive value (NPV) was high (just over $90 \%$ ) with both methods. In turn, the positive likelihood ratio (PLR) was greater for Calpro AS than for Thermo Fisher at both fCal cut-off points, and the negative likelihood ratio (NLR) was lower at the cut-off point of $50 \mu \mathrm{g} / \mathrm{g}$.

\section{Stability study at room temperature}

With regard to the comparative study between recent fecal extracts and extracts after 4 days at room temperature, Figure $2 \mathrm{a}$ shows the Passing-Bablok adjusted scatter plot of the results of fCal. The y-intercept does pass through 0 (from 0.4406 to 0.8922 with $95 \% \mathrm{CI}$ ), thus reflecting the absence of differences between the two extracts. The Spearman correlation coefficient $(\rho)$ was 0.951 (95\% CI: 0.933 - 0.965) $(\mathrm{P}<0.0001)$. The Bland-Altman diagram between the values of recent fCal extracts and after 4 days at room temperature showed the same as in the comparison of the two methods - with dispersion increasing with the value of fCal (Fig. 2b). The histogram of the differences between the fCal determined in recent extracts and after 4 days at room temperature shows a normal distribution (Fig. 2c).

The temperature recordings at $1-\mathrm{h}$ intervals throughout the study varied between 20.3 and $27.6^{\circ} \mathrm{C}$.

The results of all the samples coincided with respect to positivity/negativity, barring two cases in which the fCal value was close to the cut-off point and which were found to be weakly positive (from 34 to 58 and from 46 to $87 \mu \mathrm{g} / \mathrm{g}$ ). The mean, median and range of fCal in the recent fecal extracts versus those kept for 4 days at room temperature were (expressed as $\mu \mathrm{g} / \mathrm{g}$ ): 104 versus 115,12 versus 14 and $5-2,179$ versus $15-2,500$.

The information supplied by the manufacturers regarding the stability of the extracts in different fCal tests was reviewed and is shown in Table 1.

\section{Discussion}

In routine clinical practice, a simple test is required to help to screen for patients with chronic intestinal symptoms such as diarrhea or abdominal pain who are amenable to more complex diagnostic tests. The colonoscopy is the reference technique for diagnosing IBD, but it is expensive, invasive and cannot be frequently repeated, particularly in children [26]. In this regard, fCal is useful as a marker in clinical practice because it is sensitive (albeit not specific) and allows us to select patients with signs and symptoms consistent with IBD that require a colonoscopy to establish the definitive diagnosis, thereby avoiding needless invasive tests in individuals with functional gastrointestinal disorders. Although the Rome IV criteria [27] classifying functional disorders as alterations in bowel-brain interaction were introduced in May 2016, our patients were classified according to the Rome III criteria [19], which had been in force for over 10 years, with important changes versus the preceding criteria, such as a reduction in the time to diagnosis [28].

In our study, although the mean and median fCal values in the group of functional disorders proved negative with both methods, being under $50 \mu \mathrm{g} / \mathrm{g}$, they exceeded $100 \mu \mathrm{g} / \mathrm{g}$ in seven cases $(6.5 \%)$ with the Calpro AS method and in 16 cases (14.9\%) with the Thermo Fisher technique. The endoscopic study identified no pathological alterations in any of them.

There is a consensus that patients with organic intestinal diseases can present fCal values above the cut-off point of 

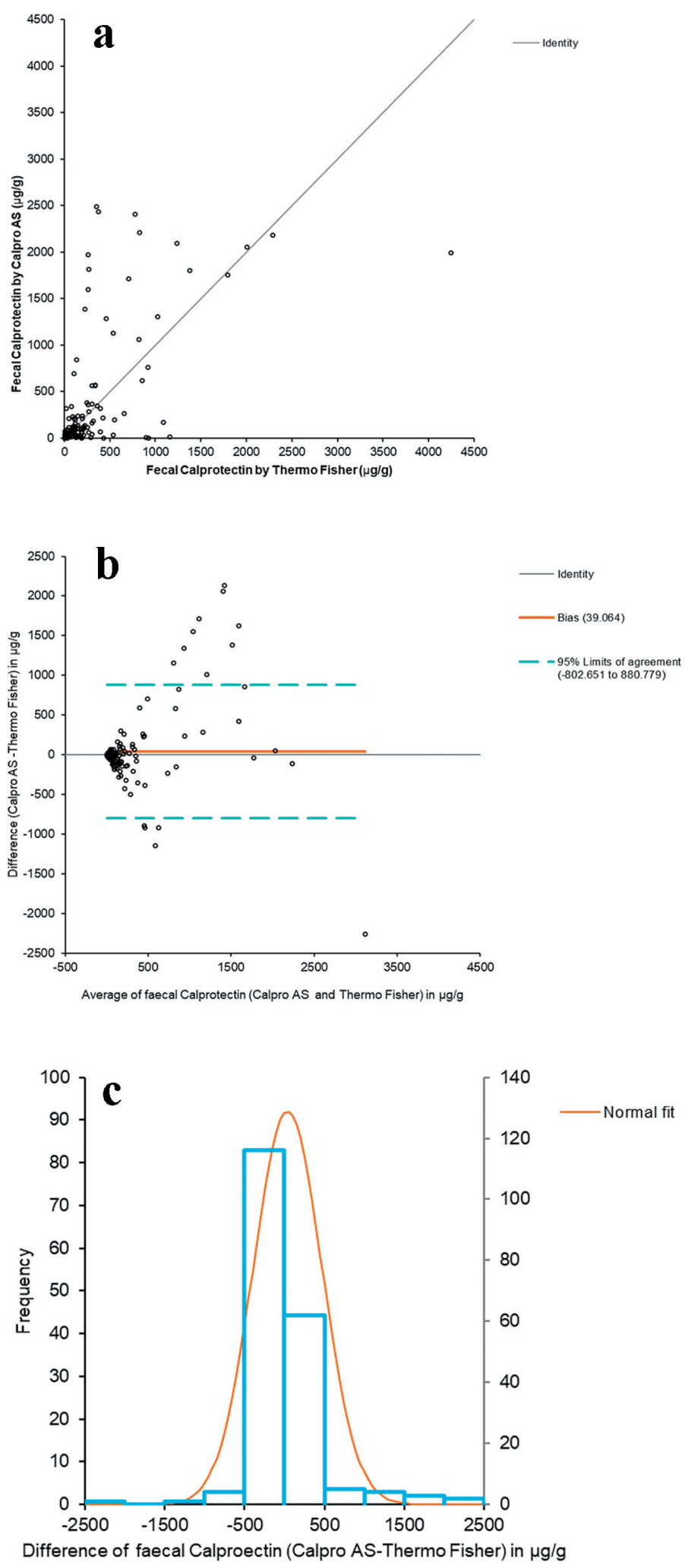

Figure 1. Comparative studies between both assays. (a) Passing-Bablok adjusted scatter plot of the fCal results obtained by Calpro AS vs. Thermo Fisher. Regression equation: $\mathrm{y}=-9.88(95 \% \mathrm{Cl}(-12.55$ to -6.18$))+1.19 \times(95 \% \mathrm{Cl}(1.00$ to 1.34$))$. Significance level: $\mathrm{P}<0.0001$. (b) Plot of differences (Bland-Altman) between Calpro AS and Thermo Fisher vs. the mean of the two measurements. (c) Histogram of differences between the two methods. 
Table 3. Stratification of the Fecal Calprotectin Results (in $\mu \mathrm{g} / \mathrm{g}$ Stools)

\begin{tabular}{lllll}
\hline \multirow{2}{*}{ Calpro AS } & \multicolumn{4}{c}{ Thermo Fisher } \\
\cline { 2 - 5 } 1 & $\mathbf{1}$ & $\mathbf{2}$ & $\mathbf{3}$ & Total \\
2 & $104^{*}$ & 3 & 8 & 115 \\
3 & 7 & $2 *$ & 9 & 18 \\
Total & 1 & 5 & $59 *$ & 65 \\
\hline
\end{tabular}

1: 0 - 49; $2: 50$ - 100; $3:>100$. *Matching results by both methods.

$50 \mu \mathrm{g} / \mathrm{g}$, with the value of $100 \mu \mathrm{g} / \mathrm{g}$ or higher being regarded as more specific $[4,22,24]$. Seven patients belonging to this group routinely used aspirin and/or NSAIDs, as well as proton pump inhibitors (such as omeprazole), which can cause side effects in the form of diarrhea, constipation and nausea. This increase in fCal, secondary to the known capacity of these drugs to cause gastrointestinal damage, has already been described [29-32], and Garcia-Sanchez et al [33] also observed considerably elevated mean fCal values for these reasons. According to the National Institute of Clinical Excellence (NICE) guidelines [34], fCal values of between 50 and 150 or $200 \mu \mathrm{g} / \mathrm{g}$ may be regarded as representative of mild organic disorders such as remitting IBD, NSAIDs-related inflammation or mild diverticulitis $[24,35]$. Patients with diverticulitis may present an acute inflammatory component that could explain the discrete increase in the levels of this marker in these individuals $[22,23,33]$.

There is uncertainty as to the optimum management of patients with borderline results (50 to $100 \mu \mathrm{g} / \mathrm{g}$ ), most of whom do not have IBD. In such cases, it is advisable to repeat the test and perform additional tests, with follow-up by the gastroenterologist [24, 35-37]. According to some authors, the gray intermediate zone of fCal reaches $200-250 \mu \mathrm{g} / \mathrm{g}$ - active IBD being considered to exist above these values [38]. There may be some variability in the recommended cut-off points, depending on the commercial kit employed [39].

The cut-off point for infants under 4 years of age is between 100 and $200 \mu \mathrm{g} / \mathrm{g}$ - positivity being defined by the presence of values $>250 \mu \mathrm{g} / \mathrm{g}$ [34] and $>500 \mu \mathrm{g} / \mathrm{g}(1-6$ months of age) [18]. From 4 years of age onwards, the fCal reference limit is similar to that applied in adults $[10,18]$. According to the technical specifications of the Calpro AS assay, sam- ples showing $>50 \mu \mathrm{g} / \mathrm{g}$ are positive, those between 50 and 100 $\mu \mathrm{g} / \mathrm{g}$ are questionable and may give rise to negative colonoscopy findings and samples presenting $>100 \mu \mathrm{g} / \mathrm{g}$ are positive - although these cases may correspond to patients in remission. In active IBD, the values are $>200 \mu \mathrm{g} / \mathrm{g}$ and may reach very high levels (up to $40,000 \mu \mathrm{g} / \mathrm{g}$ ), while the mean value in colorectal cancer patients is about $350 \mu \mathrm{g} / \mathrm{g}$. It is therefore possible for these values to overlap between the two diseases, making it impossible to distinguish between them, particularly if the values are not very high.

We therefore calculated the diagnostic tests in both methods for both cut-off points (50 and $100 \mu \mathrm{g} / \mathrm{g}$ ). The reduction in sensitivity was less pronounced for Calpro AS (5.4\% versus $7.3 \%)$ and the increase in specificity was greater $(8.4 \%$ versus $5.4 \%$ ) than for Thermo Fisher. The PPV also improved with Calpro AS (7.5\% versus 2.8\%), although the NPV fell more $(2.7 \%$ versus $2 \%)$ than for Thermo Fisher. We also calculated the accuracy of both methods - the results being higher with Calpro AS for both cut-off points (Table 4).

The Spearman correlation coefficient $(\rho)$ obtained on comparing the two methods was 0.819 (95\% CI: 0.768 - 0.860) $(\mathrm{P}<0.0001)$, reflecting a positive correlation. Similarly, when stratifying the fCal results into $<50 \mu \mathrm{g} / \mathrm{g}, 50-100 \mu \mathrm{g} / \mathrm{g}$ and $>$ $100 \mu \mathrm{g} / \mathrm{g}$, the resulting Cohen's kappa coefficient was 0.7766 (95\% CI: $0.7025-0.8507)$, reflecting a substantial agreement between both methods.

Unlike the predictive values, the likelihood ratios were not affected by disease prevalence. In our study, PLR was between 2 and 5 and NLR between 0.5 and 0.2 with both methods. Although the pre- versus post-test likelihood changes are small, they may sometimes prove to be important [40]. These observations, together with the predictive values, indicate that $\mathrm{fCal}$ is particularly useful in ruling out IBD in the presence of a negative result [37].

In relation to the diagnosis of IBD in adult patients, the World Gastroenterology Organisation practice guideline includes the determination of fCal among the indicated laboratory tests: "these evaluations (fCal together with lactoferrin and alpha-1-antitrypsin) may be more effective in ruling out intestinal inflammation than when used as a positive diagnostic test" [41]. This guideline also describes fCal as a simple, reliable and readily available test for measuring the activity of IBD - possibly being better in application to UC than to CD. Like other studies $[18,33]$, we obtained higher fCal values in $\mathrm{UC}$ than in $\mathrm{CD}$.

Table 4. Test Performance of the Fecal Calprotectin Assays With Two Cut-Off Values

\begin{tabular}{lllll}
\hline & Calpro AS & Thermo Fisher & Calpro AS & Thermo Fisher \\
\hline Fecal calprotectin cut-off $(\mu \mathrm{g} / \mathrm{g})$ & 50 & 50 & 100 & 100 \\
Sensitivity $(\%)$ & 78.2 & 81.8 & 67.3 & 74.5 \\
Specificity (\%) & 74.8 & 68.8 & 83.2 & 75.5 \\
Accuracy (\%) & 77.2 & 69.7 & 79.3 & 75.3 \\
Positive predictive value (\%) & 53.8 & 51.1 & 61.3 & 53.9 \\
Negative predictive value (\%) & 90.2 & 90.5 & 87.5 & 88.5 \\
Positive likelihood ratio (\%) & 2.9 & 2.6 & 4.1 & 3.1 \\
Negative likelihood ratio (\%) & 0.29 & 0.43 & 0.37 & 0.34 \\
\hline
\end{tabular}



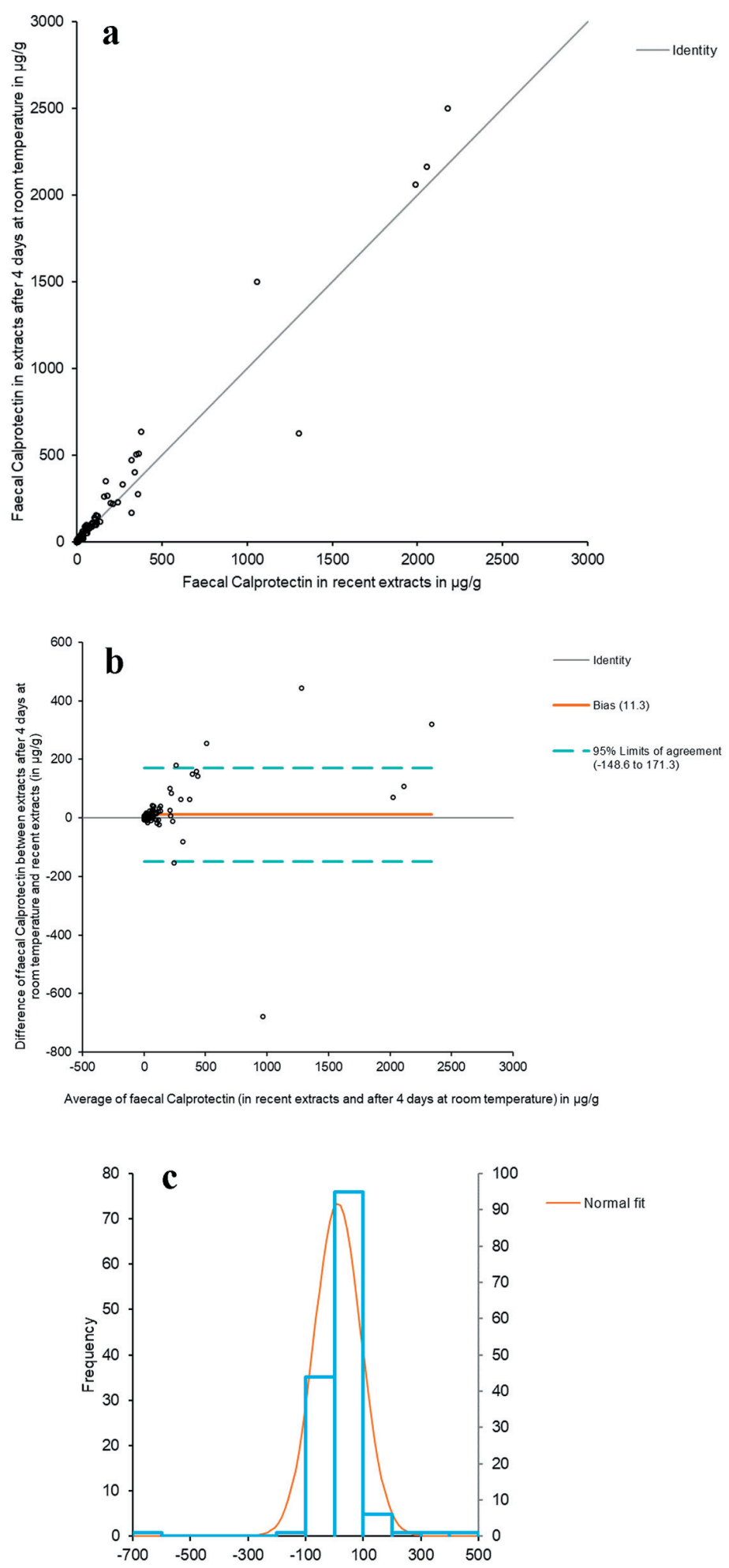

Difference of faecal Calprotectin (in extracts after 4 days at room temperature-recent extracts ) in $\mu \mathrm{g} / \mathrm{g}$

Figure 2. Comparative study between recent fecal extracts and extracts after 4 days at room temperature. (a) The Passing-Bablok scatter plot of fCal results in recent fecal extracts and after 4 days at room temperature, determined by Calpro AS. Regression equation: $\mathrm{y}=0.24(95 \% \mathrm{Cl}(-0.44$ to 0.89$))+1.15 \times(95 \% \mathrm{Cl}(1.08$ to 1.21$))$. Significance level: $P<0.0001$. (b) Bland-Altman diagram between the values of recent fCal extracts and after 4 days at room temperature. (c) Histogram of differences between the two measurements. 
On the other hand, $\mathrm{fCal}$ is known to remain stable in recent stool samples ( $3-7$ days in the refrigerator or several months at $-20{ }^{\circ} \mathrm{C}$, depending on the laboratory). However, fecal extract stability varies according to the buffer used by the manufacturer, as can be seen in Table 1. Thermo Fisher advises against refrigeration at between 2 and $8^{\circ} \mathrm{C}$, even for one night, since this results in a decrease in fCal concentration. Even DIASorin instructs that its extracts should not be frozen, while DiaSource, in reference to its quantitative fCal ELISA, specifies that its stool sample collection tube can be transported at room temperature, although it does not indicate for how many days. At present, only Calpro EasyExtract (Calpro AS) and Calex Cap (Bulmann) describe stability at room temperature for 5 and 3 days, respectively.

The stability of fCal was high in fecal extracts with the Calpro AS extraction buffer at room temperature for 4 days, which yielded a Spearman correlation coefficient of 0.951 (95\% CI: 0.933 - 0.965) when the results were compared to those of the recent extracts $(\mathrm{P}<0.0001)$.

\section{Conclusions}

A positive correlation was observed between the two methods. In view of the high negative predictive value obtained with $\mathrm{fCal}$, the presence of organic disease is highly unlikely in the presence of a normal concentration of this marker. It is therefore ideal for avoiding invasive techniques and is of particular interest in pediatric patients. We also confirmed the excellent stability of fCal in fecal extracts with the Calpro AS extraction buffer stored at room temperature. Thus, for the sake of convenience and hygiene, it would be ideal for the patient to perform the extraction at home.

The symptoms of intestinal disorders are relatively nonspecific (e.g., dyspepsia, diarrhea or abdominal pain). It is therefore important and profitable to distinguish between patients with functional diseases, which do not require invasive methods, and those with organic disorders - particularly IBD. The fCal testing should not be used on an isolated basis but in combination with other clinical, endoscopic, radiological and/ or histological parameters, thus permitting a comprehensive evaluation of the patient.

\section{Acknowledgments}

The authors would like to thank Menarini Diagnostics for its technical support in the conduction of this study.

\section{Conflict of Interest}

The authors state that they have no conflict of interest.

\section{References}

1. Manceau H, Chicha-Cattoir V, Puy H, Peoc'h K. Fecal calprotectin in inflammatory bowel diseases: update and perspectives. Clin Chem Lab Med. 2017;55(4):474-483.

2. D'Angelo F, Felley C, Frossard JL. Calprotectin in Daily Practice: Where Do We Stand in 2017? Digestion. 2017;95(4):293-301.

3. Lehmann FS, Burri E, Beglinger C. The role and utility of faecal markers in inflammatory bowel disease. Therap Adv Gastroenterol. 2015;8(1):23-36.

4. Jahnsen J, Roseth AG, Aadland E. [Measurement of calprotectin in faeces]. Tidsskr Nor Laegeforen. 2009;129(8):743-745.

5. Dale I, Brandtzaeg P, Fagerhol MK, Scott H. Distribution of a new myelomonocytic antigen (L1) in human peripheral blood leukocytes. Immunofluorescence and immunoperoxidase staining features in comparison with lysozyme and lactoferrin. Am J Clin Pathol. 1985;84(1):24-34.

6. Naess-Andresen CF, Egelandsdal B, Fagerhol MK. Calcium binding and concomitant changes in the structure and heat stability of calprotectin (L1 protein). Clin Mol Pathol. 1995;48(5):M278-284.

7. Rodrigo L. [Fecal calprotectin]. Rev Esp Enferm Dig. 2007;99(12):683-688.

8. Bonnin Tomas A, Vila Vidal M, Rosell Camps A. [Fecal calprotectin as a biomarker to distinguish between organic and functional gastrointestinal disease]. Rev Esp Enferm Dig. 2007;99(12):689-693.

9. Gisbert JP, McNicholl AG. Questions and answers on the role of faecal calprotectin as a biological marker in inflammatory bowel disease. Dig Liver Dis. 2009;41(1):5666.

10. Sherwood RA. Faecal markers of gastrointestinal inflammation. J Clin Pathol. 2012;65(11):981-985.

11. Roseth AG, Fagerhol MK, Aadland E, Schjonsby H. Assessment of the neutrophil dominating protein calprotectin in feces. A methodologic study. Scand J Gastroenterol. 1992;27(9):793-798.

12. Kristensen V, Lauritzen T, Jelsness-Jorgensen LP, Frigstad SO, Corwin C, Moum B. Patient-performed extraction of faecal calprotectin. Clin Chem Lab Med. 2016;54(8):1357-1363.

13. Li F, Ma J, Geng S, Wang J, Liu J, Zhang J, Sheng X. Fecal calprotectin concentrations in healthy children aged 1-18 months. PLoS One. 2015;10(3):e0119574.

14. Zhu Q, Li F, Wang J, Shen L, Sheng X. Fecal calprotectin in healthy children aged 1-4 years. PLoS One. 2016;11(3):e0150725.

15. Oord T, Hornung N. Fecal calprotectin in healthy children. Scand J Clin Lab Invest. 2014;74(3):254-258.

16. Hestvik E, Tumwine JK, Tylleskar T, Grahnquist L, Ndeezi G, Kaddu-Mulindwa DH, Aksnes L, et al. Faecal calprotectin concentrations in apparently healthy children aged 0-12 years in urban Kampala, Uganda: a community-based survey. BMC Pediatr. 2011;11:9.

17. Fagerberg UL, Loof L, Merzoug RD, Hansson LO, Finkel Y. Fecal calprotectin levels in healthy children studied with an improved assay. J Pediatr Gastroenterol Nutr. 2003;37(4):468-472.

18. Krzesiek E. Fecal calprotectin as an activity marker of inflammatory bowel disease in children. Adv Clin Exp 
Med. 2015;24(5):815-822.

19. Mostafa R. Rome III: The functional gastrointestinal disorders, third edition, 2006. World J Gastroenterol. 2008;14(13):2124-2125.

20. Walmsley RS, Ayres RC, Pounder RE, Allan RN. A simple clinical colitis activity index. Gut. 1998;43(1):29-32.

21. Harvey RF, Bradshaw JM. A simple index of Crohn'sdisease activity. Lancet. 1980;1(8167):514.

22. Walsham NE, Sherwood RA. Fecal calprotectin in inflammatory bowel disease. Clin Exp Gastroenterol. 2016;9:21-29.

23. Manz M, Burri E, Rothen C, Tchanguizi N, Niederberger C, Rossi L, Beglinger C, et al. Value of fecal calprotectin in the evaluation of patients with abdominal discomfort: an observational study. BMC Gastroenterol. 2012;12:5.

24. von Roon AC, Karamountzos L, Purkayastha S, Reese GE, Darzi AW, Teare JP, Paraskeva P, et al. Diagnostic precision of fecal calprotectin for inflammatory bowel disease and colorectal malignancy. Am J Gastroenterol. 2007;102(4):803-813.

25. McHugh ML. Interrater reliability: the kappa statistic. Biochem Med (Zagreb). 2012;22(3):276-282.

26. Henderson P, Anderson NH, Wilson DC. The diagnostic accuracy of fecal calprotectin during the investigation of suspected pediatric inflammatory bowel disease: a systematic review and meta-analysis. Am J Gastroenterol. 2014;109(5):637-645.

27. Drossman DA, Hasler WL. Rome IV-Functional GI disorders: disorders of gut-brain interaction. Gastroenterology. 2016;150(6):1257-1261.

28. Baber KF, Anderson J, Puzanovova M, Walker LS. Rome II versus Rome III classification of functional gastrointestinal disorders in pediatric chronic abdominal pain. J Pediatr Gastroenterol Nutr. 2008;47(3):299-302.

29. Tacheci I, Kopacova M, Rejchrt S, Bures J. Non-steroidal anti-inflammatory drug induced injury to the small intestine. Acta Medica (Hradec Kralove). 2010;53(1):3-11.

30. Mukherjee S. Diarrhea associated with lansoprazole. J Gastroenterol Hepatol. 2003;18(5):602-603.

31. Waldum HL, Arnestad JS, Brenna E, Eide I, Syversen U, Sandvik AK. Marked increase in gastric acid secretory ca- pacity after omeprazole treatment. Gut. 1996;39(5):649653.

32. Molero Gomez R, Sacristan de Lama, MP, Lopez Arranz C, Mangues Bafalluy I, Socias Manzano MS, Pineiro Corrales G. Utilizacion terapeutica del omeprazol. Farm Hosp. 1997;21(5):243-256.

33. Garcia Sanchez MV, Gonzalez R, Iglesias Flores E, Gomez Camacho F, Casais Juanena L, Cerezo Ruiz A, Montero Perez-Barquero M, et al. Precision diagnostica de la Calprotectina fecal para predecir una colonoscopia patologica. Med Clin (Barc). 2006;127(2):41-46.

34. National Institute for Health and Clinical Excellence (NICE). Diagnostics guidance 11. Faecal Calprotectin diagnostic tests for inflammatory diseases of the bowel. October 2013.

35. Pujalte P, Calabuig S. Catlab informa. 2015; Butlleti $\mathrm{N}^{\circ} 65$. Mes desembre.

36. Pavlidis P, Chedgy FJ, Tibble JA. Diagnostic accuracy and clinical application of faecal calprotectin in adult patients presenting with gastrointestinal symptoms in primary care. Scand J Gastroenterol. 2013;48(9):10481054.

37. Waugh N, Cummins E, Royle P, Kandala NB, Shyangdan D, Arasaradnam R, Clar C, et al. Faecal calprotectin testing for differentiating amongst inflammatory and non-inflammatory bowel diseases: systematic review and economic evaluation. Health Technol Assess. 2013;17(55):xv-xix, 1-211.

38. Benitez JM, Garcia-Sanchez V. Faecal calprotectin: Management in inflammatory bowel disease. World J Gastrointest Pathophysiol. 2015;6(4):203-209.

39. Labaere D, Smismans A, Van Olmen A, Christiaens P, D'Haens G, Moons V, Cuyle PJ, et al. Comparison of six different calprotectin assays for the assessment of inflammatory bowel disease. United European Gastroenterol J. 2014;2(1):30-37.

40. Ruiz de Adana R. Eficacia de una prueba diagnostica: parametros utilizados en el estudio de un test. Jano. 2009; Mayo $\mathrm{N}^{\circ}$ 1.736:30-32.

41. World Gastroenterology Organisation (WGO). 2015; Practice Guideline - Inflammatory Bowel Disease (IBD). 